\title{
Celebrating 50 Years of Publication: Year in Review!
}

\author{
Joseph Gorsuch $^{1}$ - Daniel J. Call ${ }^{2}$ (i)
}

Received: 10 November 2016 / Accepted: 11 November 2016 / Published online: 23 November 2016

(C) Springer Science+Business Media New York 2016

You might recall reading the editorial, Celebrating 50 Years of Publication! (Call and Gorsuch 2016), in the January 2016 issue of the Bulletin of Environmental Contamination and Toxicology (Bulletin). Our editorial announced plans to celebrate the Bulletin's 50th Year Anniversary. As the Golden Anniversary year of the Bulletin closes, we are honored to have served as its Anniversary volume Editors. Several changes that were implemented to commemorate this special year are described below.

Each issue contained editorials or retrospectives helping to celebrate 50 years of publication. Editorials reflecting the Bulletin's history were published by two former editors-inchief (Hylin 2016; Nigg 2016) and an overview of the future of the Bulletin was presented by current editor-in-chief (Bennett 2016a, b). Other editorials were on ecotoxicology in the US southern states (Garcia-Reyero 2016), and the risk of neonicotinoid insecticides (Kurwadkar and Evans 2016).

In addition to the six editorials, nine retrospectives were prepared by past Bulletin authors, or associates, with papers in the top 100 citations that described the advancement of science and regulations during the past 20-40 years to protect the environment (Chapman 2016; Heinz 2016; LeBlanc 2016; Rattner et al. 2016; Schmitt and Mckee 2016; Schultz and Aptula 2016; Shore and Shemesh 2016; Stehle and Schulz 2016; Zitko 2016). These papers addressed some of the most important environmental science research of the last $30-50$ years.

Daniel J. Call

dcall@enviro-analysts.com

1 Gorsuch Environmental Management Systems, Webster, NY 14580, USA

2 Environmental Research \& Information Analysts, LLC, Dubuque, IA 52001, USA
Focused reviews were announced as a new publishing option in April (Bennett 2016a). Five reviews were published in this anniversary year, with the first appearing in the May issue (Faust et al. 2016). These were followed by reviews in July (Mathieu-Denoncourt et al. 2016), September (Duan et al. 2016), October (Furtado et al. 2016), and December (Greaves and Letcher 2016). Two reviews focused on metals, two on organics, and one on potential implications of climate change on new water legislation in the United States.

Additionally, seven articles that were published during the year, including the retrospective by Schultz and Aptula and focused reviews from May, September and October, were selected by the editors to highlight the breadth of the papers the Bulletin receives and publishes. The remaining three articles were by Schmitt and McKee (2016), Lüderwald et al. (2016), and Rios et al. 2016. The editorials, retrospectives and selected papers were available for download through open access. These retrospectives and selected papers have generated considerable interest as evidenced by download records, with one paper having been downloaded 1300 times as of October 31st.

In 2017 we anticipate publishing additional retrospectives prepared by authors with highly cited Bulletin papers during the past 20-30 years. We'll close by recognizing the outstanding support of the many authors that have made the Bulletin a cherished resource of old and new research, and wishing the Bulletin continued success for decades to come. The articles we've highlighted showcase the types of papers published in the Bulletin, and we encourage you, the reader, to consider submitting your paper to the Bulletin of Environmental Contamination and Toxicology.

Joseph W Gorsuch and Daniel J Call

50th Anniversary Volume Editors 


\section{References}

Bennett ER (2016a) The bulletin of environmental contamination and toxicology: the next chapter. Bull Environ Contam Toxicol 96:421-422

Bennett ER (2016b) A letter from the editor-in-chief: in this issue of BECT. Bull Environ Contam Toxicol 97:1

Call DJ, Gorsuch JW (2016) Celebrating 50 years of publication! Bull Environ Contam Toxicol 96:1-2

Chapman PM (2016) Sediment contaminant bioaccumulation: with or without gut contents? Bull Environ Contam Toxicol 97:151-152

Duan Q, Lee J, Liu Y, Chen H, Hu H (2016) Distribution of heavy metal pollution in surface soil samples in China: a graphical review. Bull Environ Contam Toxicol 97:303-309

Faust DR, Moore MT, Emison GA, Rush SA (2016) Potential implications of approaches to climate change on the clean water rule definition of "Waters of the United States". Bull Environ Contam Toxicol 96:565-572

Furtado LM, Bundschuh M, Metcalfe CD (2016) Monitoring the fate and transformation of silver nanoparticles in natural waters. Bull Environ Contam Toxicol 97:449-455

Garcia-Reyero N (2016) Advancing ecotoxicology in the US southern states. Bull Environ Contam Toxicol 96:705-706

Greaves AK, Letcher RJ (2016) A review of organophosphate esters in the environment for biological effects to distribution and fate. Bull Environ Contam Toxicol 97. doi:10.1007/ s00128-016-1898-0

Heinz GH (2016) A downstream voyage with mercury. Bull Environ Contam Toxicol 97:591-592

Hylin J (2016) Origin of the bulletin of environmental contamination and toxicology. Bull Environ Contam Toxicol 96:137-138

Kurwadkar S, Evans A (2016) Neonicotinoids: systemic insecticides and systematic failure. Bull Environ Contam Toxicol 97. doi:10.1007/s00128-016-1968-3

LeBlanc GA (2016) Retrospective: acute toxicity of priority pollutants. Bull Environ Contam Toxicol 97:301-302
Lüderwald S, Seitz F, Seisenbaeva GA, Kessler VG, Schulz R, Bundschuh M (2016) Palladium nanoparticles: is there a risk for aquatic ecosystems? Bull Environ Contam Toxicol 97:153-158

Mathieu-Denoncourt J, Wallace SJ, de Solla SR, Langlois VS (2016) Influence of lipophilicity on the toxicity of bisphenol A and phthalates to aquatic organisms. Bull Environ Contam Toxicol 97:4-10

Nigg H (2016) A most interesting and wonderful time as an editor. Bull Environ Contam Toxicol 96:271-272

Rattner BA, Wiemeyer SN, Blus LJ (2016) Retrospective: adjusting contaminant concentrations in bird eggs to account for moisture and lipid loss during their incubation. Bull Environ Contam Toxicol 97:2-3

Rios JHL, Marins RV, Oliveira KF, Lacerda LD (2016) Long-term (2002-2015) changes in mercury contamination in NE Brazil depicted by the mangrove oyster Crassostraea rhizophorae (Guilding, 1828). Bull Environ Contam Toxicol 97:474-479

Schmitt CJ, McKee MJ (2016) Concentration trends for lead and calcium-normalized lead in fish fillets from the Big River, a miningcontaminated stream in southeastern Missouri USA. Bull Environ Contam Toxicol 97:597-600

Schultz TW, Aptula AO (2016) Kinetic-based reactivity for Michael acceptors: structural activity relationships and its relationship to excess acute fish toxicity. Bull Environ Contam Toxicol 97. doi:10.1007/s00128-016-1871-y

Shore LS, Shemesh M (2016) Estrogen as an environmental pollutant. Bull Environ Contam Toxicol 97:447-448

Stehle S, Schulz R (2016) Global insecticide surface water contamination assessment: BECT's contribution in the last five decades. Bull Environ Contam Toxicol 96:563-564

Zitko V (2016) Reminiscence of forty years of environmental chemistry. Bull Environ Contam Toxicol 97. doi:10.1007/ s00128-016-1971-8 